\title{
Nutritional and antioxidative properties of black goat meat cuts
}

\author{
Hye-Jin Kim ${ }^{1}$, Hee-Jin Kim ${ }^{1}$, and Aera Jang ${ }^{1, *}$
}

\begin{abstract}
* Corresponding Author: Aera Jang Tel: +82-33-250-8643, Fax: +82-33-251-7719,

E-mail: ajang@kangwon.ac.kr
\end{abstract}

' Department of Animal Life Science, College of Animal Life Science, Kangwon National University, Chuncheon 24341, Korea

ORCID

Hye-Jin Kim

https://orcid.org/0000-0002-9384-6720

Hee-Jin Kim

https://orcid.org/0000-0002-6959-9790

Aera Jang

https://orcid.org/0000-0003-1789-8956

Submitted Dec 18, 2018; Revised Feb 15, 2019; Accepted Mar 5, 2019
Objective: In this study, we evaluated the nutritional value and antioxidant activity of black goat loin (BGL) and black goat rump (BGR) meat.

Methods: We evaluated the proximate compositions, collagen and mineral contents, and fatty acid compositions of BGL and BGR with respect to their nutritional value. The levels of bioactive compounds such as L-carnitine, creatine, creatinine, carnosine, and anserine were also measured. The ferric reducing antioxidant power (FRAP), 2,2-azinobis (3-ethylbenzothiazoline-6-sulfonic acid) (ABTS) radical scavenging, and oxygen radical absorption capacity (ORAC) were assessed to evaluate the antioxidant activity of BGL and BGR.

Results: BGR showed higher collagen, Fe, Ca, P, and Na contents than did BGL $(\mathrm{p}<0.05)$. Notably, the $\mathrm{Ca} / \mathrm{P}$ ratio was high in both BGR and BGL (1.82 and 1.54, respectively), thus satisfying the recommendation that the $\mathrm{Ca} / \mathrm{P}$ ratio is between 1 and 2 . BGL showed a significantly higher content of desirable fatty acids (stearic acid and total unsaturated fatty acids) than did BGR. In addition, the levels of creatine, carnosine, and anserine in BGL were higher than those in $B G R(p<0.05)$. There was no significant difference in the antioxidant activity between BGL and BGR, as assessed by FRAP (both $15.92 \mu \mathrm{mol}$ Trolox equivalent [TE]/g of dry matter [DM]), ABTS (12.51 and $12.90 \mu \mathrm{mol} \mathrm{TE} / \mathrm{g}$ DM, respectively), and ORAC (101.25 and $99.06 \mu \mathrm{mol}$ TE/g DM, respectively) assays.

Conclusion: This was a primary study conducted to evaluate the differences in nutritional value and antioxidant activity between loin and rump cuts of black goat meat. Our results provide fundamental knowledge that can help understand the properties of black goat meat.

Keywords: Black Goat Meat; Bioactive Compound; Antioxidant Activity; Nutritional Value; Mineral

\section{INTRODUCTION}

Goats have been together with humans for the consumption since the beginning of human civilization [1]. The Korean native goat (Capra hircus coreanae) is a breed of goats indigenous to Korea; approximately $80 \%$ of the population is predominantly black. Archaeological evidence on the origin of the Korean black goat is not available. However, historical literature indicates that the history of goat farming on the Korean Peninsula may date back over 2,000 years [2]. Korean black goats have been raised in the mountains on agricultural byproducts and native grass. With the recent increase in consumption of black goat meat, fulltime farming of black goats has also increased in Korea [3].

Goat meat tends to be dark red in color and possesses a rough texture, with a flavor and aroma perceptibly different from those of lamb and mutton [4]. Goat meat is widely consumed in Asia and developing countries. Black goats have a low carcass weight, and the meat has a strong wild flavor. Most Korean people consume black goat meat in the form of meat and bone extracts rather than the meat itself. The extract of black goat meat has been considered a folk medicine and is used to improve the health of young children, pregnant women, and the elder population. The health benefits of these extracts may be due to their low con- 
tent of fat and high levels of amino acids such as arginine, leucine, and isoleucine; the extracts also contain high contents of protein and minerals such as $\mathrm{Ca}$ and $\mathrm{Fe}$ [3].

Studies on black goat meat have evaluated the quality of loin [1], physicochemical properties [4,5], and methods to extract black goat meat for medicinal use [6,7]. However, there have been limited studies evaluating the nutritional values of different cuts of black goat meat and their antioxidant properties. Therefore, in this study, we evaluated the nutritional value and antioxidant activity of black goat loin (BGL) and black goat rump (BGR) meat cuts.

\section{MATERIALS AND METHODS}

\section{Preparation of black goat meat}

Twenty-four hours post-mortem, BGL and BGR cuts each from three different black goats (14-month-old, male) were obtained from a local meat market. Surface fat and connective tissue were dissected away from each meat sample, and the remaining meat samples were minced finely using a food processor (HMF-3800SS; Hanil, Seoul, Korea). The minced meat samples were stored at $-20^{\circ} \mathrm{C}$ until analysis.

\section{Nutritional values}

Evaluation of proximate composition: Proximate compositions of BGL and BGR were evaluated using the Official Methods of Analysis stipulated by the Association of Official Agricultural Chemists (AOAC) [8]. The moisture content was assessed using oven drying of samples at $105^{\circ} \mathrm{C}$ for $16 \mathrm{~h}$, and the crude protein content was analyzed by the Kjeldahl method using a conversion factor of 6.25 . Crude fat was assayed by solvent extraction, and crude ash was analyzed using a furnace at $550^{\circ} \mathrm{C}$ for $12 \mathrm{~h}$.

Evaluation of collagen content: The collagen content was determined by measuring hydroxyproline according to the method of Kim et al [9]. Briefly, each meat sample (5 g) was hydrolyzed with $30 \mathrm{~mL}$ of $7 \mathrm{~N}$ sulfuric acid for $16 \mathrm{~h}$ at $105^{\circ} \mathrm{C}$. One milliliter of an acid-hydrolyzed diluted sample was mixed with $0.5 \mathrm{~mL}$ of $1.41 \%$ chloramine $\mathrm{T}$ in a collagen buffer solution ( $\mathrm{pH}$ 6.0), containing sodium hydroxide (15 g), sodium acetate trihydrate $(90 \mathrm{~g})$, citric acid monohydrate $(30 \mathrm{~g})$, and 1-propanol $(290 \mathrm{~mL})$ per $1 \mathrm{~L}$ of water. The mixture was shaken for $20 \mathrm{~min}$ at $23^{\circ} \mathrm{C} \pm 1^{\circ} \mathrm{C}$, then mixed with $0.5 \mathrm{~mL}$ of the reactive color reagent ( $5 \mathrm{~g}$ of 4-dimethylaminobenzaldehyde, $17.5 \mathrm{~mL}$ of $60 \%$ sulfuric acid, and $32.5 \mathrm{~mL}$ of 2-propanol) and incubated in a water bath at $60^{\circ} \mathrm{C}$ for $15 \mathrm{~min}$. After the reaction was completed, absorbance was measured at $558 \mathrm{~nm}$ using a spectrophotometer (SpectraMax M2e; Molecular Devices, Sunnyvale, CA, USA). The hydroxyproline content was calculated using a standard curve, and the collagen content in the samples was calculated using a correction factor of 8.0.

Mineral content: To analyze the contents of $\mathrm{Fe}, \mathrm{Ca}, \mathrm{P}, \mathrm{K}$, and
$\mathrm{Na}$ in BGL and BGR, $2 \mathrm{~g}$ of each meat sample was ashed at $550^{\circ} \mathrm{C}$. The ashed meat samples were dissolved in $65 \%$ nitric acid, and the solutions were transferred into $100-\mathrm{mL}$ volumetric flasks, making up to volume with distilled water. The mineral contents in the diluted solutions were analyzed using an inductively coupled plasma optical emission spectrometer (Optima 7300 DV; PerkinElmer, Schwerzenbach, Switzerland).

Fatty acid composition: To determine the fatty acid composition, $2 \mathrm{~g}$ of each meat sample was homogenized in $15 \mathrm{~mL}$ of Folch solution (chloroform/methyl alcohol, 2:1, v/v) containing $40 \mu \mathrm{L}$ of tert-butyl-4-hydroxyanisole and then filtered through Whatman No. 1 filter paper (Clifton, NJ, USA). Each filtered sample was mixed with $2 \mathrm{~mL}$ of $0.88 \% \mathrm{KCl}$ and shaken vigorously. The separated bottom layer was dried under nitrogen gas, and fatty acid methyl ester (FAME) derivatives were generated via methylation of fatty acids with boron trifluoride in methanol for $1 \mathrm{~h}$ at $90^{\circ} \mathrm{C}$. FAMEs were analyzed using a gas chromatograph $(6890 \mathrm{~N}$; Agilent Technologies, Santa Clara, CA, USA) equipped with a CP-Sil 88 capillary column $(100 \mathrm{~m} \times 0.25 \mathrm{~mm}$ id $\times 0.20 \mu \mathrm{m}$ film thickness; Agilent CP7489, Agilent Technologies, USA) and a flame ionization detector. The initial oven temperature was $150^{\circ} \mathrm{C}$, which was then increased to $200^{\circ} \mathrm{C}$ at a rate of $7^{\circ} \mathrm{C} / \mathrm{min}$, held at $200^{\circ} \mathrm{C}$ for $20 \mathrm{~min}$, increased to $250^{\circ} \mathrm{C}$ at a rate of $3^{\circ} \mathrm{C} / \mathrm{min}$, and held at $250^{\circ} \mathrm{C}$ for $5 \mathrm{~min}$. The injector and detector temperatures were $260^{\circ} \mathrm{C}$ and $280^{\circ} \mathrm{C}$, respectively. Helium was used as a carrier gas at a flow rate of $1 \mathrm{~mL} / \mathrm{min}$, and $1 \mu \mathrm{L}$ of each sample was injected at a splitting ratio of 1:100. Each fatty acid was identified via matching its retention time with that of a respective standard using a commercially available mixture of fatty acids (PUFA No. 2-Animal Source; Supelco, Bellefonte, PA, USA).

L-carnitine content: The L-carnitine content was analyzed in the meat samples according to the method of Shimada et al [10], with slight modifications. Briefly, $5 \mathrm{~g}$ of each sample was homogenized in $25 \mathrm{~mL}$ of $0.3 \mathrm{M}$ perchloric acid (PCA) on ice. After centrifugation at $1,140 \times g$ for $10 \mathrm{~min}$, the supernatant was filtered through a glass microfiber filter (GF/C; Whatman, USA), and then the pellet was re-extracted with $20 \mathrm{~mL}$ of $0.3 \mathrm{M}$ PCA. The volume of the pooled supernatants was adjusted to $50 \mathrm{~mL}$ with $0.3 \mathrm{M}$ PCA. One milliliter of the extract was neutralized with $1.2 \mathrm{M} \mathrm{K}_{2} \mathrm{CO}_{3}$. After centrifugation at $8,385 \times \mathrm{g}$ for $10 \mathrm{~min}$, the supernatant was filtered through a $0.45-\mu \mathrm{m}$ membrane filter. The standard or sample $(50 \mu \mathrm{L})$ was loaded with $50 \mu \mathrm{L}$ of a reaction buffer, containing $0.93 \mathrm{mM} 5,5^{\prime}$-dithiobis-(2-nitrobenzoic acid), $0.55 \mathrm{mM}$ acetyl-CoA, $3.05 \mathrm{mM}$ ethylenediaminetetraacetic acid, and 610 $\mathrm{mM}$ Tris- $\mathrm{HCl}, \mathrm{pH} 7.5$, in a 96-well microplate. The blank absorbance of the samples was measured at $415 \mathrm{~nm}$ using a SpectraMax M2e spectrophotometer (Molecular Devices, USA) after incubation at $37^{\circ} \mathrm{C}$ for $10 \mathrm{~min}$. For the enzymatic reaction, $25 \mu \mathrm{L}(0.5 \mathrm{U})$ of carnitine acetyltransferase (EC 
2.3.1.7; Sigma, St. Louis, MO, USA) was added, and the mixture was incubated at $37^{\circ} \mathrm{C}$ for $30 \mathrm{~min}$. The final absorbance was measured at $415 \mathrm{~nm}$, and the difference between the blank and final absorbance was used to calculate the content of Lcarnitine. L-carnitine was purchased from Sigma Co. (USA) to generate a standard curve.

Creatine, creatinine, and dipeptide contents: Creatine, creatinine, and dipeptide (carnosine and anserine) contents were measured using the method of Mora et al [11] with slight modifications. Briefly, $2.5 \mathrm{~g}$ of a meat sample was homogenized with $7.5 \mathrm{~mL}$ of $0.01 \mathrm{~N} \mathrm{HCl}$, and the homogenate was centrifuged at $3,000 \times g$ for $30 \mathrm{~min}$. The supernatant was filtered through a glass microfiber filter (GF/C; Whatman, USA), and then $250 \mu \mathrm{L}$ of the filtrate was deproteinized by incubation with $750 \mu \mathrm{L}$ of acetonitrile for $20 \mathrm{~min}$ at $4^{\circ} \mathrm{C}$. The sample was centrifuged at $10,000 \times g$ for $10 \mathrm{~min}$, and the supernatant was filtered through a $0.22-\mu \mathrm{m}$ membrane filter before analysis. The contents of creatine, creatinine, and dipeptides (carnosine and anserine) were analyzed using a liquid chromatograph (1260 Infinity; Agilent Technologies, USA), equipped with an Atlantis HILIC silica column $(4.6 \times 150 \mathrm{~mm} \times 3 \mu \mathrm{m}$; Waters, Milford, MA, USA), at the column temperature of $35^{\circ} \mathrm{C}$. Mobile phase A was $0.65 \mathrm{mM}$ ammonium acetate ( $\mathrm{pH}$ 5.5) in water/acetonitrile $(25: 75, \mathrm{v} / \mathrm{v})$, and mobile phase $\mathrm{B}$ was 4.55 $\mathrm{mM}$ ammonium acetate ( $\mathrm{pH}$ 5.5) in water/acetonitrile (70:30, $\mathrm{v} / \mathrm{v})$. We used a linear gradient of phase B from $0 \%$ to $100 \%$ over $13 \mathrm{~min}$ at a flow rate of $1.4 \mathrm{~mL} / \mathrm{min}$. Creatine, carnosine, and anserine were detected at $214 \mathrm{~nm}$, and creatinine was detected at $236 \mathrm{~nm}$ using a diode array detector (Agilent Technologies, USA). The contents were calculated using a standard curve generated for each respective standard (Sigma, USA).

\section{Antioxidant activities}

Preparation of meat samples for determining antioxidant activities: To determine the antioxidant activities, $4 \mathrm{~g}$ of each meat sample was homogenized in $20 \mathrm{~mL}$ of distilled water. The homogenates were filtered through Whatman No. 4 filter paper (USA), followed by the addition of $4 \mathrm{~mL}$ of chloroform and vortexing. The bottom layer was lyophilized and stored at $-20^{\circ} \mathrm{C}$ until use.

Ferric reducing antioxidant power activity: The ferric reducing antioxidant power (FRAP) assay was carried out according to the method of Benzie and Strain [12], with slight modifications. The FRAP working solution contained $300 \mathrm{mM}$ acetate buffer ( $\mathrm{pH}$ 3.6), $10 \mathrm{mM}$ 2,4,6-tripyridyl-S-triazine in $40 \mathrm{mM} \mathrm{HCl}$, and a $20 \mathrm{mM} \mathrm{FeCl}_{3} \cdot 6 \mathrm{H}_{2} \mathrm{O}$ solution at a ratio of 10:1:1 (v/v/v), respectively. Each meat extract $(25 \mu \mathrm{L})$ was reacted with $175 \mu \mathrm{L}$ of the FRAP working solution for $30 \mathrm{~min}$ at $37^{\circ} \mathrm{C}$ in the dark. The absorbance of the reaction solution was determined at $590 \mathrm{~nm}$ using a spectrophotometer (Molecular Devices, USA). The standard curve was obtained using
Trolox (Sigma, USA). The results were expressed as micromoles of Trolox equivalent (TE) per gram of dry matter (DM).

2,2-Azinobis (3-ethyl-benzothiazoline-6-sulfonic acid) radical-scavenging activity: To analyze the 2,2-azinobis (3-ethylbenzothiazoline-6-sulfonic acid) (ABTS) radical-scavenging activity, we used the method of Re et al [13] with some modifications. To generate the $\mathrm{ABTS}^{+}$radical, a stock solution was made by mixing equal volumes of a $14 \mathrm{mM} \mathrm{ABTS}^{+}$solution and a $5.9 \mathrm{mM}$ potassium persulfate solution; the resulting solution was then reacted at $23^{\circ} \mathrm{C} \pm 1^{\circ} \mathrm{C}$ for $12 \mathrm{~h}$ in the dark. The stock solution was diluted with distilled water to an absorbance of $0.700 \pm 0.02$ at $735 \mathrm{~nm}$, as assessed using a spectrophotometer (Molecular Devices, USA) at $30^{\circ} \mathrm{C}$. Meat extracts $(50 \mu \mathrm{L})$ were reacted with $950 \mu \mathrm{L}$ of the $\mathrm{ABTS}^{+}$radical solution for $30 \mathrm{~min}$ at $30^{\circ} \mathrm{C}$ in the dark. The absorbance of the reaction solution was determined at $735 \mathrm{~nm}$, and the results were expressed as micromoles of TE per gram of DM.

Oxygen radical absorption capacity: The oxygen radical absorption capacity (ORAC) assay was performed according to the method of Gillespie et al [14], with some modifications, using $75 \mathrm{mM}$ potassium phosphate buffer $(\mathrm{pH} 7.4)$ at $37^{\circ} \mathrm{C}$. First, $25 \mu \mathrm{L}$ of a meat extract was mixed with $150 \mu \mathrm{L}$ of $80 \mathrm{nM}$ fluorescein. After incubation at $37^{\circ} \mathrm{C}$ for $15 \mathrm{~min}, 25 \mu \mathrm{L}$ of 150 $\mathrm{mM} 2,2^{\prime}$-azobis (2-amidinopropane) hydrochloride (AAPH) was added to generate peroxyl radicals. The change in the absorbance of the reaction was recorded every minute at an excitation wavelength of $480 \mathrm{~nm}$ and emission wavelength of $520 \mathrm{~nm}$ at $37^{\circ} \mathrm{C}$ using a SpectraMax M2e spectrophotometer (Molecular Devices, USA). Trolox was used as a standard, and the results were expressed as micromoles of TE per gram of DM.

\section{Statistical analysis}

Statistical analysis was performed using the SAS program version 9.4 (SAS Institute, Inc., Cary, NC, USA). Data comparison was performed using a Student's $t$-test. Differences among means were considered significant at $\mathrm{p}<0.05$. All data are expressed as the mean \pm standard error of the mean.

\section{RESULTS AND DISCUSSION}

\section{Proximate compositions and collagen and mineral contents of black goat loin and black goat rump} The proximate compositions and collagen and mineral contents of BGL and BGR are shown in Table 1. BGL and BGR contained $75.00 \%$ and $75.49 \%$ moisture, $21.60 \%$ and $21.30 \%$ crude protein, $1.48 \%$ and $1.40 \%$ crude fat, and $1.41 \%$ and $1.25 \%$ ash, respectively, with no significant differences between the cuts. Similarly, Choi et al [15] have reported that the proximate composition of black goat meat included $74.40 \%$ to $76.04 \%$ moisture, $19.83 \%$ to $20.47 \%$ crude protein, $1.64 \%$ to $3.56 \%$ crude fat, and $1.04 \%$ to $1.11 \%$ crude ash. Hwang et 
Table 1. Proximate compositions and collagen and mineral contents of different meat cuts from black goats

\begin{tabular}{lccc}
\hline \multirow{2}{*}{ Traits } & \multicolumn{2}{c}{ Cuts } & \multirow{2}{*}{ SEM } \\
\cline { 2 - 3 } & BGL & BGR & \\
\hline Proximate composition (\%) & & & \\
$\quad$ Moisture & $75.00^{\mathrm{a}}$ & $75.49^{\mathrm{a}}$ & 0.281 \\
Crude protein & $21.60^{\mathrm{a}}$ & $21.30^{\mathrm{a}}$ & 0.743 \\
Crude fat & $1.48^{\mathrm{a}}$ & $1.40^{\mathrm{a}}$ & 0.071 \\
Crude ash & $1.41^{\mathrm{a}}$ & $1.25^{\mathrm{a}}$ & 0.076 \\
Collagen (g/100 g) & $0.59^{\mathrm{b}}$ & $1.12^{\mathrm{a}}$ & 0.010 \\
Minerals (mg/100 g) & & & \\
Fe & $1.35^{\mathrm{b}}$ & $1.48^{\mathrm{a}}$ & 0.003 \\
Ca & $5.22^{\mathrm{b}}$ & $6.09^{\mathrm{a}}$ & 0.029 \\
P & $3.39^{\mathrm{a}}$ & $3.34^{\mathrm{a}}$ & 0.015 \\
K & $325.22^{\mathrm{a}}$ & $281.40^{\mathrm{b}}$ & 0.700 \\
$\mathrm{Na}$ & $76.03^{\mathrm{b}}$ & $94.97^{\mathrm{a}}$ & 0.215 \\
Ca:P & $1.54^{\mathrm{b}}$ & $1.82^{\mathrm{a}}$ & 0.008 \\
\hline
\end{tabular}

BGL, black goat loin; BGR, black goat rump; SEM, standard error of the mean. $a, b$ Means with different superscript letters within a row are significantly different at $p<0.05$.

al [16] have reported that the crude fat content of black goat meat was between $1.12 \%$ and $1.59 \%$, which agrees with our results. On the other hand, Kim et al [5] have reported that the crude fat content of the BGL meat was $7.81 \%$ to $9.43 \%$ at the different age of castration, which was higher than our values. Another study has reported that the proximate composition of goat meat included $67.0 \%$ to $75.2 \%$ moisture, $18.9 \%$ to $24.8 \%$ crude protein, $3.25 \%$ to $12.6 \%$ crude fat, and $0.95 \%$ to $1.19 \%$ crude ash, depending on the breed [17].

The collagen content of BGR was higher than that of BGL $(p<0.05)$, which may be due to higher exercise status of the rump muscle compared with that of the loin muscle in black goats. Our data are similar to the results of Cho et al [18] showing that the beef rump showed a higher collagen content than the loin did because of the difference in exercise strength between them. Generally, the goat meat has a higher content and lower solubility of collagen compared with those in the sheep meat, which is linked to lower tenderness of goat meat compared with that of sheep meat and may explain the lower consumer preference for goat meat [1].

Minerals are essential for maintaining the normal growth and a good health. Lean meat is an excellent source of minerals. The feed type and breed of the animal can affect the mineral content of meat. The $\mathrm{Fe}, \mathrm{Ca}, \mathrm{P}, \mathrm{K}$, and $\mathrm{Na}$ contents in BGL and BGR are shown in Table 1. Red meat can contain a high level of bioavailable Fe, which is abundant in red meats such as lean beef $(2.72 \mathrm{mg} / 100 \mathrm{~g})$, lamb $(1.74 \mathrm{mg} / 100$ $\mathrm{g})$, veal $(1.11 \mathrm{mg} / 100 \mathrm{~g})$, and goat $(4.37 \mathrm{mg} / 100 \mathrm{~g})$ [19]. In this study, the Fe content in BGR (1.48 mg/100 g) was significantly $(\mathrm{p}<0.05)$ higher than that in BGL $(1.35 \mathrm{mg} / 100 \mathrm{~g})$. Jeong et al [3] have reported that the Fe content in black goat meat was $0.6 \mathrm{mg} / 100 \mathrm{~g}$, which is lower than that observed in our study. Ca and $\mathrm{P}$ are major minerals required for bone development, and the ideal $\mathrm{Ca} / \mathrm{P}$ ratio, based on the recommended daily allowance of nutrients, is between 1 and 2 [19]. In this study, the $\mathrm{Ca} / \mathrm{P}$ ratio in both $\mathrm{BGL}$ and $\mathrm{BGR}$ (1.54 and 1.82 , respectively) satisfied the recommended criteria, while being higher in BGR than in BGL $(\mathrm{p}<0.05)$. Fresh meat is also a rich source of $\mathrm{K}$, and its contents in beefsteak, mutton, and goat meat were shown to be 334,240 , and $350 \mathrm{mg} / 100 \mathrm{~g}$, respectively [19]. In this study, the K content in BGL (325.22 $\mathrm{mg} / 100 \mathrm{~g})$ was higher than that in BGR $(281.40 \mathrm{mg} / 100 \mathrm{~g}$; $\mathrm{p}<0.05)$. BGR showed a higher content of $\mathrm{Na}$ than BGL did $(\mathrm{p}<0.05)$.

\section{Fatty acid compositions of black goat loin and black goat rump}

The fatty acid composition of meat can influence its organoleptic properties and quality. The fatty acid compositions of BGL and BGR are shown in Table 2 . The predominant fatty acids in BGL and BGR were palmitic acid, stearic acid, oleic acid, linoleic acid, and arachidonic acid. The contents of oleic acid and monounsaturated fatty acids (MUFAs) in the meat are positively associated with its organoleptic properties [4].

Table 2. Fatty acid compositions of different meat cuts from black goats

\begin{tabular}{lccc}
\hline \multirow{2}{*}{ Fatty acid (\%) } & \multicolumn{2}{c}{ Cuts } & \multirow{2}{*}{ SEM } \\
\cline { 2 - 3 } & BGL & BGR & \\
\hline C14:0 (myristic acid) & $1.37^{\mathrm{b}}$ & $2.14^{\mathrm{a}}$ & 0.079 \\
C16:0 (palmitic acid) & $21.36^{\mathrm{b}}$ & $23.05^{\mathrm{a}}$ & 0.302 \\
C16:1n7 (palmitoleic acid) & $0.88^{\mathrm{b}}$ & $1.22^{\mathrm{a}}$ & 0.031 \\
C18:0 (stearic acid) & $16.35^{\mathrm{a}}$ & $14.94^{\mathrm{b}}$ & 0.222 \\
C18:1n9 (oleic acid) & $30.00^{\mathrm{a}}$ & $28.76^{\mathrm{a}}$ & 0.328 \\
C18:1n7 (vaccenic acid) & $5.84^{\mathrm{a}}$ & $5.18^{\mathrm{a}}$ & 0.312 \\
C18:2n6 (linoleic acid) & $10.48^{\mathrm{a}}$ & $11.64^{\mathrm{a}}$ & 0.359 \\
C18:3n6 ( $\gamma$-linolenic acid) & $0.07^{\mathrm{b}}$ & $0.08^{\mathrm{a}}$ & 0.003 \\
C18:3n3 (a-linolenic acid) & $0.15^{\mathrm{a}}$ & $0.18^{\mathrm{a}}$ & 0.008 \\
C20:1n9 (eicosenoic acid) & $1.84^{\mathrm{a}}$ & $1.83^{\mathrm{a}}$ & 0.206 \\
C20:4n6 (arachidonic acid) & $9.88^{\mathrm{a}}$ & $9.04^{\mathrm{a}}$ & 0.431 \\
C20:5n3 (eicosapentaenoic acid) & $0.35^{\mathrm{a}}$ & $0.30^{\mathrm{a}}$ & 0.019 \\
C22:4n6 (adrenic acid) & $1.43^{\mathrm{a}}$ & $1.59^{\mathrm{a}}$ & 0.055 \\
C22:6n3 (docosahexaenoic acid) & $0.00^{\mathrm{b}}$ & $0.05^{\mathrm{a}}$ & 0.000 \\
SFA & $39.07^{\mathrm{a}}$ & $40.13^{\mathrm{a}}$ & 0.350 \\
UFA & $60.93^{\mathrm{a}}$ & $59.87^{\mathrm{a}}$ & 0.350 \\
MUFA & $38.56^{\mathrm{a}}$ & $36.99^{\mathrm{a}}$ & 0.541 \\
PUFA & $22.37^{\mathrm{a}}$ & $22.89^{\mathrm{a}}$ & 0.860 \\
MUFA/SFA & $0.99^{\mathrm{a}}$ & $0.92^{\mathrm{b}}$ & 0.008 \\
PUFA/SFA & $0.57^{\mathrm{a}}$ & $0.57^{\mathrm{a}}$ & 0.026 \\
DFA & $77.27^{\mathrm{a}}$ & $74.81^{\mathrm{b}}$ & 0.358 \\
\hline Data a the means & & &
\end{tabular}

Data are the means $(n=3)$.

BGL, black goat loin; BGR, black goat rump; SEM, standard error of the mean; SFA, saturated fatty acid; UFA, unsaturated fatty acid; PUFA, polyunsaturated fatty acid; MUFA, monounsaturated fatty acid; DFAs, desirable fatty acids (stearic acid+UFAs).

$a, b$ Means with different superscript letters within a row are significantly different at $p<0.05$. 
In this study, the oleic acid contents in BGL and BGR were $30.00 \%$ and $28.76 \%$, respectively. These levels were slightly lower than the range of $37.23 \%$ to $39.80 \%$ previously reported for black goat meat [16], regular goat meat [1], and beef [20]. BGR showed higher contents of myristic acid, palmitic acid, palmitoleic acid, $\gamma$-linolenic acid, and docosahexaenoic acid than did BGL $(p<0.05)$, while BGL showed a higher stearic acid content than did BGR $(\mathrm{p}<0.05)$. However, there were no significant differences in the levels of total saturated fatty acids (SFA) and unsaturated fatty acids (UFAs) between BGR and BGL. The polyunsaturated fatty acid (PUFA)/SFA ratio is used to evaluate the nutritional quality of fat in meat, and the recommended value is more than 0.4 or 0.5 [21]. In addition, the American Heart Association recommends a fatty acid balance of SFAs, MUFAs, and PUFAs of approximately 1:1.5:1. In this study, BGL and BGR contained $39.07 \%$ and 40.13\% SFAs and $22.37 \%$ and $22.89 \%$ PUFAs, respectively, showing the same PUFA/SFA ratio of 0.57 , as compared with the previously reported ranges of 0.31 to 0.37 for goat loin meat and 0.31 to 0.49 for goat rump meat [22]. BGL and BGR also showed a higher PUFA/SFA ratio than beef did at 0.13 [20]. High dietary intake of long-chain SFAs, except stearic acid, has been associated with an increase in plasma cholesterol levels in humans [23]. Oleic acid is known to reduce cholesterol by suppressing low-density lipoprotein cholesterol and triglycerides, and stearic acid is partially converted to oleic acid in vivo [23]. Therefore, desirable fatty acids (DFAs), which represent a total of stearic acid and all UFAs, are considered another factor of nutritional quality of fat for humans because of their ability to reduce plasma cholesterol levels [22]. Generally, the DFA content ranges in goat meat from $61 \%$ to $80 \%$ [22]. In this study, BGL showed a higher DFA content than did BGR (77.27\% and 74.81\%, respectively; $\mathrm{p}<0.05)$, and both values were higher than those reported for beef and lamb (63.80\% and 61.58\%, respectively) [20]. Therefore, black goat meat can provide a balanced content of fatty acids for human consumption.

\section{Bioactive compounds in black goat loin and black goat rump}

The bioactive compounds (L-carnitine, creatine, creatinine, carnosine, and anserine) found in BGL and BGR are shown in Table 3. As a ubiquitous constituent of mammalian plasma, supplied by dietary meat and dairy products [10], L-carnitine supports the transport of long-chain fatty acids from the outer to the inner mitochondrial membrane, allowing $\beta$-oxidation of long-chain fatty acids [24]. The level of L-carnitine can be considered a major factor in cellular energy production using long-chain fatty acids. Generally, red meat is known as an abundant source of L-carnitine. In this study, the BGL and BGR meats contained L-carnitine at 1.37 and $1.25 \mu \mathrm{mol} / \mathrm{g}$ wet tissue, respectively. According to Shimada et al [10], the
Table 3. Bioactive compounds in different meat cuts from black goats

\begin{tabular}{lccc}
\hline \multirow{2}{*}{ Traits } & \multicolumn{2}{c}{ Cuts } & \multirow{2}{*}{ SEM } \\
\cline { 2 - 3 } & BGL & BGR & \\
\hline L-carnitine $^{1)}$ & $1.37^{\mathrm{a}}$ & $1.25^{\mathrm{a}}$ & 0.041 \\
Creatine $^{2)}$ & $187.87^{\mathrm{a}}$ & $178.26^{\mathrm{b}}$ & 1.342 \\
Creatinine $^{2}$ & $3.13^{\mathrm{a}}$ & $2.97^{\mathrm{b}}$ & 0.023 \\
Carnosine & $65.25^{\mathrm{a}}$ & $49.54^{\mathrm{b}}$ & 1.481 \\
Anserine & $81.93^{\mathrm{a}}$ & $66.32^{\mathrm{b}}$ & 1.825 \\
Carnosine:anserine & $0.80^{\mathrm{a}}$ & $0.75^{\mathrm{b}}$ & 0.002 \\
\hline
\end{tabular}

BGL, black goat loin; BGR, black goat rump; SEM, standard error of the mean.

${ }^{1)}$ The $\mathrm{L}$-carnitine content is expressed in $\mu \mathrm{mol} / \mathrm{g}$ wet tissue.

${ }^{2)}$ Creatine, creatinine, carnosine, and anserine contents are expressed in $\mathrm{mg} / 100 \mathrm{~g}$ wet tissue.

$a, b$ Means with different superscript letters within a row are significantly different at $p<0.05$.

content of L-carnitine in fresh semitendinosus muscles of cattle varies from 1.67 to $3.57 \mu \mathrm{mol} / \mathrm{g}$ wet tissue.

Creatine and its phosphorylated form creatinine are important for energy production in muscles, and supplementation with creatine can help enhance the muscle performance [25]. In our study, BGL contained creatine at $187.87 \mathrm{mg} / 100 \mathrm{~g}$, which was significantly higher than its content in BGR $(178.26 \mathrm{mg} /$ $100 \mathrm{~g}$ ). Meanwhile, the creatinine content was 3.13 and 2.97 $\mathrm{mg} / 100 \mathrm{~g}$ in BGL and BGR, respectively, showing no significant difference. The creatine and creatinine contents have been reported to vary in animals, as follows: pork loin (427.32 and $5.71 \mathrm{mg} / 100 \mathrm{~g}$, respectively) [11], chicken breast (336.24 and $1.78 \mathrm{mg} / 100 \mathrm{~g}$, respectively) [11], and beef (526 and $21 \mathrm{mg} /$ $100 \mathrm{~g}$, respectively) [25].

Carnosine and anserine are dipeptides, which provide a buffering capacity in skeletal muscles. Carnosine shows antiglycation activity and antioxidant properties, such as scavenging of reactive oxygen species and chelating metal ions [25]. Anserine functions as an antioxidant in humans by chelating $\mathrm{Cu}$ [25]. In this study, the carnosine and anserine contents of BGL (62.25 and $81.93 \mathrm{mg} / 100 \mathrm{~g}$, respectively) were higher than those of BGR (49.54 and $66.32 \mathrm{mg} / 100 \mathrm{~g}$, respectively; $\mathrm{p}<0.05)$. Mora et al [11] have reported that the contents of carnosine, creatine, and creatinine in different muscles of swine were primarily affected by the muscle type. Glycolytic muscles such as type $2 \mathrm{~A}$ and type $2 \mathrm{~B}$ show high contents of carnosine, creatine, and creatinine. Similarly, in this study, BGL (glycolytic muscle) showed a higher content of carnosine, creatine, and creatinine than did BGR $(\mathrm{p}<0.05)$. The carnosine and anserine contents were 462 and $10.76 \mathrm{mg} / 100 \mathrm{~g}$ [11] and 372 and $67 \mathrm{mg} / 100 \mathrm{~g}$ [25] in pork loin and beef, respectively. Thus, the carnosine and anserine contents vary in different species. Generally, red meats such as pork and beef have a high carnosine-to-anserine ratio, 42.9 [11] and 5.5 [25], respectively. Interestingly, in this study, the carnosine-to-anserine ratios in BGL and BGR, another type of red meat, were 0.80 
and 0.75, respectively, i.e., BGL and BGR contained more anserine than carnosine. This pattern is similar to that found in rabbit and red deer meat (ratios of 0.44 and 0.73 , respectively) [26]. These results suggested that BGL could provide more bioactive compounds than BGR could, and both BGL and BGR showed similar carnosine/anserine ratios to those found in rabbits and red deer.

\section{Antioxidant activities of black goat loin and black goat rump}

The antioxidant activities of BGL and BGR are shown in Table 4. The FRAP, ABTS, and ORAC methods are often used to evaluate the antioxidant activity of foods. The FRAP method is based on the reduction of a ferroin analog and can measure the total reducing capacity [27]. The ABTS method is used to measure the ability of hydrogen-donating antioxidants to scavenge the $\mathrm{ABTS}^{+}$radical cation generated in the aqueous phase [27]. The ORAC method is used to measure the antioxidant activity against peroxyl radicals generated by AAPH and is the most biologically relevant method for analyzing antioxidant activity [28]. Intake of antioxidants helps maintain an adequate antioxidant status and prevent cellular damage from oxidative stress generated in the body [28]. In our study, the FRAP, ABTS, and ORAC values for BGL and BGR were 15.92 and $15.92,12.51$ and 12.90 , and 101.25 and $99.06 \mu \mathrm{mol}$ $\mathrm{TE} / \mathrm{g} \mathrm{DM}$, respectively, showing that there was no significant difference in the antioxidant activity between BGL and BGR. Mirzaei et al [29] have reported that goat meat had $42 \%$ diphenyl-picrylhydrazyl radical-scavenging activity. In our previous study, boiled pork meat showed a FRAP activity of 3.66 to $5.31 \mu \mathrm{mol} \mathrm{TE} / \mathrm{g}$ DM, ABTS activity of 26.60 to 39.43 $\mu \mathrm{mol} \mathrm{TE} / \mathrm{g} \mathrm{DM}$, and an ORAC activity of 143.74 to 198.35 $\mu \mathrm{mol} \mathrm{TE} / \mathrm{g}$ DM [30]. Hanwoo beef showed an ORAC activity of $145.54 \mu \mathrm{mol} \mathrm{TE} / \mathrm{g}$ DM [31]. These results indicate that black goat meat possesses a high reducing power and can help maintain an adequate antioxidant status in humans.

In this study, we evaluated nutritional values and antioxidant activities of BGL and BGR. In particular, BGL showed higher contents of DFAs, creatine, creatinine, anserine, and carnosine than did BGR. However, BGR had higher collagen and mineral contents, especially with respect to the $\mathrm{Ca} /$

Table 4. Antioxidant activities of different meat cuts from black goats

\begin{tabular}{|c|c|c|c|}
\hline \multirow{2}{*}{$\begin{array}{l}\text { Antioxidant activities } \\
(\mu \mathrm{mol} \mathrm{TE} / \mathrm{g} \mathrm{DM})\end{array}$} & \multicolumn{2}{|c|}{ Cuts } & \multirow{2}{*}{ SEM } \\
\hline & BGL & BGR & \\
\hline FRAP & 15.92 & 15.92 & 0.210 \\
\hline ABTS & 12.51 & 12.90 & 0.216 \\
\hline ORAC & 101.25 & 99.06 & 1.231 \\
\hline
\end{tabular}

$T E$, Trolox equivalent; DM, dry matter; $B G L$, black goat loin; $B G R$, black goat rump; SEM, standard error of the mean; FRAP, ferric reducing antioxidant power; ABTS, 2,2-azinobis (3-ethyl-benzothiazoline-6-sulfonic acid); ORAC, oxygen radical absorption capacity.
$P$ ratio, than did BGL. Although there was no significant difference in the antioxidant activity between BGL and BGR, both goat meat cuts showed a higher reducing power activity than did boiled pork meat [30] assessed in previous studies. This work was a novel study comparing nutritional values and antioxidant activities of black goat meat with respect to the cut. Therefore, our results help elucidate the antioxidant properties of fresh black goat meat, which is used as a nutritional food source in human consumption.

\section{CONFLICT OF INTEREST}

We certify that there is no conflict of interest with any financial organization regarding the material discussed in the manuscript.

\section{ACKNOWLEDGMENTS}

This work was supported by the National Research Foundation of Korea (NRF) grant funded by the Korea government (MEST) (NRF-2018R1A2B6008077). Also, it was supported by the MSIT (Ministry of Science and ICT), Korea, under the ITRC (Information Technology Research Center) support program (IITP-2019-2018-0-01433) supervised by the IITP (Institute for Information \& Communications Technology Promotion).

\section{REFERENCES}

1. Webb EC, Casey NH, Simela L. Goat meat quality. Small Rumin Res 2005;60:153-66. https://doi.org/10.1016/j.small rumres.2005.06.009

2. Son YS. Production and uses of Korean native black goat. Small Rumin Res 1999;34:303-8. https://doi.org/10.1016/ S0921-4488(99)00081-4

3. Jeong CH, Seo KI, Shim KH. Effects of fermented grape feeds on physico-chemical properties of Korean goat meat. J Korean Soc Food Sci Nutr 2006;35:145-9. https://doi.org/10.3746/ jkfn.2006.35.2.145

4. Kim BK, Lee JH, Jung DJ, et al. Effects of feeding herb resources powder on meat quality and sensory properties in Korean native black goat. Korean J Food Sci Anim Resour 2010;30: 811-8. https://doi.org/10.5851/kosfa.2010.30.5.811

5. Kim BK, Hwang EG, Kim SM. Meat quality and sensory properties of Korean native black goat by different castration age. Korean J Food Sci Anim Resour 2010;30:419-26. https://doi. org/10.5851/kosfa.2010.30.3.419

6. Young HT, Kim MW, Choi HJ. Studies on the characterization of black goat meat and bone beverage containing honey with red ginseng. Korean J Food Nutr 2005;18:135-9.

7. Song HN, Leem KH, Kwun IS. Effect of water extract and distillate from the mixture of black goat meat and medicinal 
herb on osteoblast proliferation and osteoclast formation. J Nutr Health 2015;48:157-66. https://doi.org/10.4163/jnh.2015. 48.2.157

8. AOAC Official methods of analysis. 16th ed. Association of Official Agricultural Chemists. Arlington, VA, USA: AOAC International; 1997.

9. Kim HJ, Kim D, Chae HS, Kim NY, Jang A. Nutritional composition in bone extracts from Jeju crossbred horses at different slaughter ages. Korean J Food Sci Anim Resour 2017; 37:486-93. https://doi.org/10.5851/kosfa.2017.37.4.486

10. Shimada K, Sakuma Y, Wakamatsu J, et al. Species and muscle differences in L-carnitine levels in skeletal muscles based on a new simple assay. Meat Sci 2004;68:357-62. https://doi.org/ 10.1016/j.meatsci.2004.04.003

11. Mora L, Sentandreu MA, Toldrá F. Hydrophilic chromatographic determination of carnosine, anserine, balenine, creatine, and creatinine. J Agric Food Chem 2007;55:4664-9. https:// doi.org/10.1021/jf0703809

12. Benzie IF, Strain JJ. The ferric reducing ability of plasma (FRAP) as a measure of "antioxidant power": the FRAP assay. Anal Biochem 1996;239:70-6. https://doi.org/10.1006/abio.1996. 0292

13. Re R, Pellegrini N, Proteggente A, et al. Antioxidant activity applying an improved ABTS radical cation decolorization assay. Free Radic Biol Med 1999;26:1231-7. https:/doi.org/ 10.1016/S0891-5849(98)00315-3

14. Gillespie KM, Chae JM, Ainsworth EA. Rapid measurement of total antioxidant capacity in plants. Nat Protoc 2007;2:86770. https://doi.org/10.1038/nprot.2007.100

15. Choi SH, Cho YM, Kim MJ, et al. Effect of castration and searing of the musk gland on growth performance and meat quality of Korean native goats. Korean J Anim Sci 2000;42: 891-6.

16. Hwang YH, Joo SH, Bakhsh A, Ismail I, Joo ST. Muscle fiber characteristics and fatty acid compositions of the four major muscles in Korean native black goat. Korean J Food Sci Anim Resour 2007;37:948-54. https://doi.org/10.5851/kosfa.2017. 37.6.948

17. Sebsibe A. Sheep and goat meat characteristics and quality. Sheep and goat production handbook for Ethiopia. Ethiopiand dheep and goats productivity improvement program (ESGPIP); Addis Ababa, Ethiopia; 2008. p. 323-8.

18. Cho SH, Seong PN, Kim JH, et al. Calorie, cholesterol, collagen, free amino acids, nucleotide-related compounds and fatty acid composition of Hanwoo steer beef with $1++$ quality grade. Korean J Food Sci Anim Resour 2008;28:333-43. https:// doi.org/10.5851/kosfa.2008.28.3.333

19. Casey NH. Goat meat in human nutrition. In: Proceedings of the V International Conference on Goats 1992; 1992 Mar; New Delhi, India.
20. Karakök SG, Ozogul Y, Saler M, Ozogul F. Proximate analysis. Fatty acid profiles and mineral contents of meats: a comparative study. J Muscle Foods 2010;21:210-23. https://doi.org/10. 1111/j.1745-4573.2009.00177.x

21.Kang G, Cho S, Seong P, et al. Effects of high pressure processing on fatty acid composition and volatile compounds in Korean native black goat meat. Meat Sci 2013;94:495-9. https:// doi.org/10.1016/j.meatsci.2013.03.034

22. Banskalieva V, Sahlu T, Goetsch AL. Fatty acid composition of goat muscles and fat depots: a review. Small Rumin Res 2000;37:255-68. https://doi.org/10.1016/S0921-4488(00)00 $128-0$

23.Mushi DE, Eik LO, Thomassen MS, Sørheim O, Ådnøy T. Suitability of Norwegian short-tail lambs, Norwegian dairy goats and Cashmere goats for meat production - carcass, meat, chemical and sensory characteristics. Meat Sci 2008;80:84250. https://doi.org/10.1016/j.meatsci.2008.03.032

24. Bremer J. Carnitine - metabolism and functions. Physiol Rev 1983;63:1420-80. https://doi.org/10.1152/physrev.1983.63.4. 1420

25. Mateescu RG, Garmyn AJ, O'neil MA, et al. Genetic parameters for carnitine, creatine, creatinine, carnosine, and anserine concentration in longissimus muscle and their association with palatability traits in Angus cattle. J Anim Sci 2012;90: 4248-55. https://doi.org/10.2527/jas.2011-5077

26.Plowman JE, Close EA. An evaluation of a method to differentiate the species of origin of meats on the basis of the contents of anserine, balenine and carnosine in skeletal muscle. J Sci Food Agric 1988;45:69-78. https://doi.org/10.1002/jsfa. 2740450109

27. Antolovich M, Prenzler PD, Patsalides E, McDonald S, Robards K. Methods for testing antioxidant activity. Analyst 2002;127: 183-98. https://doi.org/10.1039/B009171P

28. Ou B, Huang D, Hampsch-Woodill M, Flanagan JA, Deemer EK. Analysis of antioxidant activities of common vegetables employing oxygen radical absorbance capacity (ORAC) and ferric reducing antioxidant power (FRAP) assays: a comparative study. J Agric Food Chem 2002;50:3122-8. https://doi. org/10.1021/jf0116606

29. Mirzaei A, Afshoon A, Barmak MJ. Antioxidant activity of meat from chicken and goat cooked in microwave cooking system. Int J Adv Biotechnol Res 2017;8:1090-4.

30.Gil J, Kim D, Yoon SK, Ham JS, Jang A. Anti-oxidative and anti-inflammation activities of pork extracts. Korean J Food Sci Anim Resour 2016;36:275-82. https://doi.org/10.5851/ kosfa.2016.36.2.275

31. Kim HJ, Yang SR, Jang A. Anti-proliferative effect of a novel anti-oxidative peptide in Hanwoo beef on human colorectal carcinoma cells. Korean J Food Sci Anim Resour 2018;38: 1168-78. https://doi.org/10.5851/kosfa.2018.e48 